\title{
ENTRE A HISTÓRIA E A LITERATURA: UM DIÁLOGO COM A OBRA THE SECRET DIARY OF ANNE BOLEYN (1997]
}

\author{
BETWEEN HISTORY AND LITERATURE: A DIALOGUE \\ WITH THE NOVEL THE SECRET DIARY OF ANNE BOLEYN (1997)
}

\section{RESUMO}

O presente artigo se propõe a observar o diálogo entre história e literatura a partir do romance The Secret Diary of Anne Boleyn, da escritora inglesa Robin Maxwell. Com efeito, percebemos que as conclusões de um romancista podem contribuir em certos aspectos para a produção historiográfica, ao oferecerem um importante testemunho da época/período no qual determinada obra fora composta. Nesse caso, pretende-se mostrar como a visão da autora sobre a vida de Ana Bolena contribuiu para que ela recriasse uma história de quase 500 anos, sobre um ponto de vista atual e influenciado pelas ideias de liberdade e força feminina das últimas décadas. Para tanto, usou-se o conceito de representação segundo Chartier (1991) para investigar como Ana Bolena, segunda esposa de Henrique VIII, foi inserida na obra de Maxwell, migrando assim do campo da história para o da literatura e se apresentando como um exemplo de heroína trágica para os tempos modernos.

Palavras-chave: Ana Bolena; Romance; Robin Maxwell; História; Literatura.

\begin{abstract}
This article proposes to observe the dialogue between history and literature from the novel The Secret Diary of Anne Boleyn, by the English writer Robin Maxwell. In fact, we realize that the conclusions of a novelist can contribute in certain aspects to the historiographical production, by offering an important testimony of the time / period in which a given work was composed. In this case, it is intended to show how the author's view of the life of Anne Boleyn contributed to her re-creating a history of almost 500 years, from a current point of view and influenced by the ideas of freedom and feminine strength in the last few decades. For this, the concept of representation according to Chartier (1991) was used to investigate how Anne Boleyn, the second wife of Henry VIII, was inserted in Maxwell's work, thus migrating from the field of history to that of literature and presenting itself as an example of a tragic heroine for For modern times.
\end{abstract}

Keywords: Anne Boleyn; Novel; Robin Maxwell; History; Literature.

Renato Drummond Tapioca Neto

Universidade Estadual do Sudoeste da Bahia. E-mail: drummond.renato@yahoo.com.br 


\section{Introdução}

O presente artigo se propõe a observar o diálogo entre história e literatura a partir do romance The Secret Diary of Anne Boleyn, da escritora inglesa Robin Maxwell. Para tanto, partiremos de uma breve discussão sobre a relação entre História e Literatura, para explicar como um romance histórico pode contribuir para a análise do tempo vivido. Com efeito, as conclusões de um romancista podem contribuir em certos aspectos para a produção historiográfica, ao oferecerem um importante testemunho da época/período no qual determinada obra foi composta. Podemos encontrar um bom exemplo do que acaba de ser dito se tomarmos como referência a prosa de ficção de Machado de Assis e José de Alencar que, através de seus olhos e palavras, viram e registraram os acontecimentos do período em que viveram, traçando, assim, um rico painel dos costumes da sociedade brasileira oitocentista. Dessa forma, eles imortalizaram suas respectivas personagens, levando-as do plano do ficcional para o campo da história, como é o caso de Aurélia em Senhora (Alencar), ou de Capitu em Dom Casmurro (Machado), mulheres fortes que, por sua vez, contrariavam os padrões de comportamento feminino da segunda metade do século XIX.

Entretanto, quando o assunto é romance histórico, temos uma situação que difere em alguns pontos com as obras citadas acima: todas elas, ou são narradas na mesma época em que o autor as produziu, ou com uma distância temporal bastante curta. No caso de uma obra escrita com uma distância temporal longa, percebe-se com maior nitidez o olhar do presente sob um período passado, como, por exemplo, de dois ou três séculos atrás. No chamado romance histórico, há a inclusão de personalidades reais do passado, interagindo numa trama fictícia, porém, em alguns casos, baseada em pesquisa documental e bibliográfica. Sendo assim, diferentemente de livros como Senhora e Dom Casmurro, que popularizaram personagens inventadas, tornando-as posteriormente alvo de estudos literários e historiográficos, um romance histórico empreende o inverso: a transposição de uma pessoa que existiu para o campo do ficcional, tendo como pano de fundo a época na qual este indivíduo viveu. Um bom exemplo disso é Ana Bolena (1501? - 1536), rainha da Inglaterra e mãe de uma das soberanas mais famosas da história da Inglaterra, Elizabeth I.

Segundo Karen Lindsey (1995), de todas as seis esposas de Henrique VIII, Ana Bolena é a que tem atraído maior interesse popular, e sua personalidade tem sido submetida a uma distorção muito intensa. Ela já foi chamada de prostituta, conspiradora, uma plebeia que usou a religião para se promover, mas que não tinha uma convicção religiosa própria. Foi descrita como feia, deformada por uma enorme verruga escondida pela gola alta de seus vestidos e com um sexto dedo numa das mãos. Não obstante, sua história contém todos os elementos de uma novela: perseguida por um rei de cujos avanços ela resistiu no início, Ana encontrou nessa situação um meio de mudar o jogo a seu favor. Uma vez capturada, ela se transformou em captora. Tal característica, contudo, tem sido explorada em várias produções bibliográficas 
e cinematográficas, que apresentaram essa mulher ao público como dona de suas vontades, independentemente do fator de submissão feminina aos homens, marcante nas antigas sociedades da corte. Sendo assim, observaremos como Ana Bolena, personalidade real da história, migrou para o campo da Literatura, exercendo assim maior fascínio na mente do público contemporâneo, especialmente por sua trajetória marcada por elementos, tais como, o amor fundado no mútuo afeto, lutas, intriga e morte, tendo como pano de fundo a reforma da igreja em Inglaterra.

Em sua dissertação de mestrado, a historiadora Laila Brichta (2002) apontou para a problemática de se utilizar uma obra de literatura para um estudo acerca do tempo vivido. Nessa abordagem, cabe-nos perguntar: até que ponto a história contida nas páginas de um romance confere com os fatos? Esse questionamento, por sua vez, nos levar a pensar se há uma verdade na história, assunto já bastante discutido entre os pesquisadores da área das ciências humanas. Partindo do princípio de que não há conhecimento impassível de contestação, observaremos como o romance histórico oferece uma interpretação mais dinâmica acerca de determinado acontecimento, oferecendo, inclusive, pontos chave para se reinterpretar o passado e os próprios agentes que dele fizeram parte. Sendo assim, identificaremos como a romancista Robin Maxwell construiu sua narrativa, mesclando dados factuais do século XVI, reconstruídos sob a luz dos séculos XX e XXI. Para compor seu romance, Maxwell lançou mão de extensa pesquisa bibliográfica. Entre as obras que ela utiliza, podemos encontrar estudos sobre a sociedade do período, a geografia da Inglaterra no século XVI, além de biografias que abordam as vidas dos atores inseridos na trama. A pesquisa de outros historiadores foi fundamental para ela compor a sua narrativa, adicionando à mesma uma interpretação particular dos acontecimentos e preenchendo lacunas até então desconhecidas do público em geral, mas que não eram totalmente impossíveis de terem se passado.

Não obstante, entre as fontes da autora, podemos identificar despachos de embaixadores que estiveram na Inglaterra durante o período em que Ana Bolena agia como uma das principais figuras da corte henriquina, além de cartas e demais documentos do período, que servem de base para a trama da romancista. A figura da rainha Ana, na obra de Maxwell, se apresenta então como um estereótipo feminino que, por sua vez, contrastava com o ideal de inferioridade que era empregado às mulheres de então. A consulta destes trabalhos possibilitou a Robin Maxwell construir um romance no qual a história de Ana Bolena é atualizada, tornando-a próxima das mulheres da atualidade. A história de uma garota bem instruída, porém de baixa ascendência social, que não se conformou com uma postura submissa e lutou por aquilo que acreditava, a despeito das restrições que a sociedade inglesa seiscentista lhe impunha. Ao conquistar a atenção e o afeto (mesmo que temporários) de um rei, e depois uma coroa, Ana Bolena ascendeu a um posto em que várias de suas contemporâneas desejariam estar, porém com graves consequências, tanto para o Estado, quanto para si mesma. 


\section{A literatura como recurso possível para a escrita do passado}

História e literatura podem se aproximar em alguns aspectos, principalmente por seu caráter narrativo e pela representação da realidade nelas presente. Enquanto a história busca nas fontes elementos que corroborem para uma interpretação verídica do passado, a literatura, por sua vez, trilha o caminho da verossimilhança, em que as possibilidades de se "captar" o real são mais amplas do que aquelas permitidas ao historiador ${ }^{1}$. Por outro lado, conforme ressalta Roger Chartier (2011, p. 213):

Hoje, para os historiadores, a pertinência de uma interrogação sobre as relações entre história e verdade está ligada diretamente ao seu contrário, quer dizer, a sua relação com a ficção. Há diversos elementos nisso. O primeiro se prende ao fato de as obras de ficção se terem tornado objeto da história. [...] Em todo caso, a uma leitura clássica que era uma leitura fundamentalmente documental, quer dizer, em que a obra de ficção era abordada como uma reserva de informações factuais ou como uma provisão de exemplos ou de citações ilustrando um saber construído com outras técnicas, seguiu-se uma perspectiva que, segundo o termo preferido pelo New Historicism (grifo do autor), se apega à "negociação" estabelecida entre a criação estética e o mundo social. A questão inicial é, pois, compreender como cada obra é construída numa relação com as práticas comuns ou os discursos que não são alçados a registro histórico pelos contemporâneos e que se estendem à ordem do político, do judiciário, do religioso, do ritual etc.

Com efeito, em capítulo publicado no livro História: novos problemas (1988), Certeau afirma que o historiador também utiliza de estratégias ficcionais, ao selecionar ou rejeitar materiais, organizar um enredo, escolher as palavras e metáforas mais adequadas para o seu trabalho. Nesse sentido, ele entra em acordo com o pensamento de Hayden White, autor de Meta-história: a imaginação histórica do século XIX (2008). Ao analisar o trabalho histórico na Europa do século XIX, White diz na conclusão de seu livro que o historiador está determinado a escolher um ou outro dos variados meios de explicação argumentativa para elaborar a sua narrativa e assim convencer o leitor daquilo que escreve.

Tomando de empréstimo algumas das argumentações de Hayden White, Luiz Costa Lima, em História. Ficção. Literatura (2006) defende que a historiografia, devido ao seu caráter discursivo, não pode abrir mão de sua interseção com os domínios da

1 Segundo Sandra Jatahy Pesavento: “a ficção não seria [...] o avesso do real, mas uma outra forma de captá-la, onde os limites da criação e fantasia são mais amplos do que aqueles permitidos ao historiador [...]. Para o historiador a literatura continua a ser um documento ou fonte, mas o que há para ler nela é a representação que ela comporta [...] o que nela se resgata é a representação do mundo que comporta a forma narrativa” (1995, p. 117). 
ficção e da literatura, apesar de reivindicar uma veracidade dos fatos que é estranha à ficção². De acordo com Lima (2006, p. 155):

A história evidentemente se distingue da ficção enquanto está obrigada a se apoiar na evidência do acontecimento, no espaço e no tempo reais de que descreve e enquanto deve se desenvolver a partir do exame críticos de materiais recebidos da história, incluindo as análises e interpretações de outros historiadores.

Embora possuam métodos e exigências distintas, tanto a ficção quanto a história partilham dessa capacidade de cruzar formas de conhecimento e percepção sobre as coisas do mundo. Por outro lado, o recurso dos textos literários como fonte para o fazer histórico permitem ao pesquisador adentrar com maior facilidade no campo das representações. Roger Chartier, trabalhando com representação enquanto categoria de análise, a definiu como "a relação entre uma imagem presente e um objeto ausente, uma valendo pelo outro porque lhe é homóloga" (CHARTIER, 1991, p. 184).

Por ser uma escolha e, portanto, manifestação de uma ação pessoal, o historiador utiliza de estratégias ficcionais ao selecionar ou rejeitar materiais, organizar um enredo, escolher as palavras e metáforas mais adequadas para seu trabalho, etc. Assim, o profissional de história interpreta os eventos do passado, demonstrando os seus caminhos narrativos e os recursos metodológicos e teóricos por ele utilizados, viabilizando com isso uma possibilidade de se observar que essas novas abordagens e objetos de estudo utilizados na pesquisa revelam uma multiplicidade de leituras e diversas formas de escrita, que se complementam. Ainda de acordo com Chartier (2011, p. 218-19):

A constatação que inscreve a história na classe das narrativas, qualquer que seja esta história, e que marca os parentescos fundamentais que unem todas as narrativas, de qualquer natureza que sejam, tem diversas consequências essenciais. Por um lado, permite considerar como uma questão mal feita trouxe o tema do debate que foi aberto pelo artigo célebre de Lawrence Stone sobre o retorno da narração em história: se toda história é dependente das figuras e formas de narrativas, como imaginar um retorno onde não existiu partida? [...] Por outro lado, o estudo que define a história como uma narrativa abriu uma via para as análises da "poética do saber" que se esforçam por marcar, de forma precisa e usando indicadores específicos, as diferenças na forma com a qual os historiadores manejam as figuras e formas que são também as da ficção.

2 Na primeira parte de seu livro, dedicada à escrita da história, Luiz Costa Lima afirma que "a preocupação com a linguagem do historiador, com suas estratégias expressivas, não tem como precondição negalo como autor de um discurso específico e distinto do ficcional" (2006, p. 37). Seguindo essa mesma linha, Hayden White afirma que o trabalho histórico é "uma estrutura verbal na forma de um discurso narrativo em prosa" (2008, p. 11). 
A literatura também pode ser um suporte produtor de memórias, na medida em que "advinha os silêncios, os desvios e as lacunas, propositais ou não, da escrita historiográfica” (RAMOS, 2011, p. 96). Ao apostar no dilema e no paradoxo, o discurso literário abre mão da totalidade. Dessa forma, as possíveis falhas e rasuras não podem ser entendidas como "erros", e sim ferramentas sem as quais o texto literário não se constituiria na sua ambiguidade. Para Ramos (2011, p. 96):

Como potência de leitura do mundo, a escritura ficcional pode dar voz aos silenciados, aos vencidos e aos esquecidos pelo discurso hegemônico. Além disso, pode trazer à tona não só leituras compartilhadas do real (no sentido de aceitas como verdadeiras em um dado recorte temporal, espacial e social), como fazer emergir o imaginável, o possível e o impossível da "realidade", pois por ser inconcebível na sua totalidade, a dúvida e a certeza a habitam.

A literatura inflama o imaginário coletivo com novas visões e ideias, provenientes também do sonho e da fantasia, veículos do ficcional. Como registro de cunho verossímil, a literatura se dispõe "a dizer sobre o real por forma de observação direta, fruto da vivência do escritor no seu tempo", ou pela "recuperação idealizada de um passado, distante ou próximo" (RAMOS, 2011, p. 40). Com efeito, não se deve procurar no texto literário a comprovação dos fatos ali narrados, mas sim a explicação da realidade impressa nos mesmos, ou seja, a sensibilidade do escritor perante as coisas do mundo. Para Pesavento (2003, p. 35):

A história tem para com esta recriação do mundo feito texto, uma condição: é preciso que tudo tenha acontecido. O como é fruto das escolhas e estratégias ficcionais do historiador, mas é preciso que algo tenha realmente ocorrido. Assim, a História, este romance verdadeiro, como refere Paul Veyne, verdadeiramente constrói o real passado pela escritura. Na mesma linha, Michel de Certeau estabelece que, na articulação entre o discurso e o real, a escrita da história se inscreve como uma ficção ou fabricação do passado.

A história, não obstante, também pode ser entendida como uma narrativa do que aconteceu, na medida em que traduz uma alteridade no tempo, obedecendo, nesse caso, aos critérios e normas escolhidas pelo historiador. Segundo White (1994, p. 24):

O que odiscurso histórico produz são interpretações deseja qual for a informação ou o conhecimento do passado de que o historiador dispõe. Essas interpretações podem assumir numerosas formas, estendendo-se da simples crônica ou lista de fatos até "filosofias da história" altamente abstratas, mas o que todas elas têm em 
comum é seu tratamento de um modo narrativo de representação como fundamental para que se perceba seus referentes como fenômenos distintivamente "históricos".

A utilização da literatura na história também está vinculada ao modo como ela é aproveitada nos dois tipos de narrativa. Para PESAVENTO (2003, p. 40), a literatura é sempre um registro, seja ela de cunho realista, "dispondo-se a dizer sobre o real por forma de observação direta, fruto da vivência do escritor no seu tempo", seja pela "recuperação idealizada de um passado, distante ou próximo". Em The Secret Diary of Anne Boleyn, essa representação de mundo se traduz a partir das vozes de duas mulheres: Ana Bolena e sua filha, Elizabeth. A primeira delas, uma rainha consorte, a segunda, uma rainha reinante. No universo de ambas, a figura masculina era vista como escrava dos desejos mundanos, não obstante o contexto patriarcal que impunha às mulheres obediências aos homens. Enquanto os historiadores buscaram nas fontes indícios que revelassem certo fato desconhecido, Robin Maxwell, em seu papel de romancista, reescreveu tais passagens da forma como queria, sem, contudo, deixar sua narrativa incoerente.

\section{A representação da mulher em The Secret Diary of Anne Boleyn}

A história de Ana Bolena e Henrique VIII da Inglaterra já foi contada das formas mais variadas, e também veiculada em diferentes meios de informação. Dentre eles, as representações audiovisuais talvez ganhem maior destaque nestas últimas décadas do século XX e início do XXI. Todavia, antes de estrearem nos cinemas filmes como Anne of the Thousand Days (1969) ou The Other Boleyn Girl (2008), incluindo a série da Show Time, The Tudors (2007-2010), os romances históricos já exerciam fascínio na mente do público. Por meio deles, passagens até então desconhecidas da trajetória da rainha Ana puderam ser criadas tendo como base pistas deixadas pelos fatos conhecidos. Um exemplo disso seria o enredo da obra The Secret Diary of Anne Boleyn, da romancista inglesa Robin Maxwell. Com uma linguagem bastante clara e direta, a referida autora reconstrói de forma criativa a vida daquela mulher que viria a se tornar um símbolo de tragédia e heroísmo para a posteridade.

Contudo, no caso dos romances históricos, verifica-se uma apropriação de personagens reais do passado para a construção de acontecimentos e cenas registrados pelo tempo, porém dotadas de falas e/ou ações desconhecidas pelo grande público. Segundo Laila Brichta (2002, p. 7):

A escrita do passado realizada pelos romancistas, que tentam compreender a história, escrevendo-a, parece-me algo já bastante aceite. Esses romancistas, semelhante aos historiadores, elaboram o passado, seja pela apropriação de determinado conhecimento histórico presente no romance histórico tradicional, seja pela 
via do questionamento e da crítica histórica oficial, presentes na narrativa do novo romance histórico.

De acordo com o excerto acima, percebe-se como a categoria do romance histórico apresenta duas tipologias: na primeira, observamos certo acontecimento passado servindo como pano de fundo para uma trama inventada e contemporânea ao escritor; já no novo romance histórico, há uma recriação do tempo vivido, de forma reelaborada, que por muitas vezes se configura no foco principal de narrativa.

Com efeito, The Secret Diary of Anne Boleyn pode ser enquadrado na categoria do novo romance histórico, uma vez que a autora do mesmo recria os acontecimentos que marcaram a Inglaterra da primeira metade do século XVI a partir da perspectiva de uma personagem, a rainha Ana. Nas palavras de ALMEIDA (2009, p. 3) "toda a representação é necessariamente fluída e fragmentada, uma visão parcelar, dependendo dos olhos de quem vê, das suas motivações, do contexto histórico, social e mesmo linguístico de quem olhou no passado e de quem olha agora à luz do século XXI". Sendo assim, o romance apresentado por Robin Maxwell se constitui numa forma diferente de recontar fatos ocorridos em pelo menos cinco séculos atrás, mas sobre um viés mais recente e, portanto, marcado por ideologias do tempo atual, tais como a figura da mulher forte e determinada.

Filha de um cavaleiro, Sir Thomas Bolena, com uma aristocrata, Elizabeth Howard, Ana Bolena é uma dessas mulheres que passam pela história por um curto período de tempo, mas que deixaram profundas marcas durante esse percurso. Como Maria Antonieta, ela catalisa um imenso interesse por parte das pessoas em sua vida, ou melhor, na sua desgraça. Decapitada em 19 de maio de 1536, ela surge na cultura popular do século XXI como uma heroína trágica, adorável para alguns, e desprezível para outros. Segundo Susan Bordo (2013, p. xiii),

Why is Anne Boleyn so fascinating? Maybe we don't have to go any further than the obvious: The story of her rise and fall is as elementally satisfying - and scriptwise, not very different from - a Lifetime movie: a long-suffering, postmenopausal, wife; an unfaithful husband and a clandestine affair with a younger sexier woman; a moment of glory for the mistress; then lust turned to loathing, plotting, and murder as the cycle comes full circle.

Dessa forma, seguindo a linha de raciocínio de Bordo, a história de Ana Bolena é repleta de elementos que, por sua vez, são um convite para romancistas e cineastas escreverem e produzirem trabalhos que tenham como tema a ascensão e queda da segunda esposa de Henrique VIII, no meio do palco da reforma religiosa na Inglaterra.

Mas quem era Ana Bolena? Eis uma questão que nem os seus biógrafos, entre eles Eric Ives (2010) e Antonia Fraser (2010), conseguiram chegar a obter conclusão comum. Através dos anos que se seguiram à sua morte (1536), a figura dela vem 
ganhando características multifacetadas (sendo, inclusive, criticada, ou até mesmo difamada, por alguns historiadores mais tradicionais que jogam para o campo da irrelevância sua fundamental contribuição na formação da nova instituição religiosa que despontava naquele reino). Em grande parte referindo-se a ela como "a amante do rei" e não como a rainha que foi (mesmo que por um curto período), alguns a chamaram de bruxa, outros de meretriz, e também há quem diga que foi uma das maiores consortes que a Inglaterra já conheceu³.

É seguindo essa linha de raciocínio que Robin Maxwell oferece para os seus leitores uma personagem feminina forte, porém alvo de inúmeras calúnias, devido ao fato de se apresentar não como uma filha e esposa submissa, mas alguém predestinada a tomar as rédeas do próprio destino. Nas cortes europeias do século XVI, era comum dizer que uma mulher tinha dois donos em sua vida: primeiro o pai, a quem deveria total obediência até o momento em que se casasse, passando então a ser propriedade do esposo pelo fim de sua vida. Se acontecesse de enviuvar, nesse caso, poderia gozar de certa independência, mas mesmo assim bastante limitada (LINDSEY, 1995, p. 55). Segundo ALMEIDA (2009, p. 4-6), Ana Bolena, entretanto, fugiu a esse padrão e talvez o ódio que muitas de suas contemporâneas sentiam por ela se devia ao fato de que elas também almejavam a tais prerrogativas, embora fossem frustradas pelas circunstâncias. Afinal, não era qualquer uma que tinha o privilégio de ser o alvo das atenções do rei de Inglaterra e, não obstante, saber conservá-lo.

No entanto, The Secret Diary of Anne Boleyn não traz apenas uma figura de mulher forte no seu enredo, e sim de duas, uma vez que a obra, no primeiro momento, não está contextualizada no reinado de Henrique VIII, mas no da filha deste: a rainha Elizabeth I. A trama se inicia quando Elizabeth, recém-entronada, sofrendo com uma paixão proibida por Robert Dudley e dividida entre a política e o sentimento, recebe de uma antiga camareira de sua mãe, Lady Sommerville, um suposto diário que Ana Bolena escreveu desde quando deixou o serviço da rainha de França para integrar o séquito de Catarina de Aragão, até a sua morte 14 anos depois. O mais interessante nesse aspecto é que, por meio da narrativa ficcional, Robin Maxwell construiu uma relação entre mãe e filha da qual a história não tem registro. Quando Ana Bolena morreu, Elizabeth tinha cerca de três anos incompletos, de modo que deveria se recordar muito pouco da fisionomia de sua progenitora, além do fato de ter crescido no estigma de ser uma bastarda e filha de uma mulher adúltera.

Dessa forma, o diário criado por Maxwell seria uma forma da nova rainha da Inglaterra conhecer mais o passado de sua mãe, além de encontrar as respostas para seus próprios problemas pessoais. Nas páginas do suposto livro de segredos, a personagem Ana Bolena fala em primeira pessoa, conforme podemos observar a partir deste trecho:

3 Na introdução da sua Dissertação de Mestrado, Ana Paula Lopes de Almeida diz que "a imagem de Ana Bolena tem sido maltratada ao longo dos séculos - o seu estereótipo como 'coquete', 'vulgar' e 'adúltera' prevaleceu ao longo dos tempos", contudo, "alguns historiadores, biógrafos e romancistas têm recentemente olhado para Ana de uma forma diferente, recuperando a sua representação e reconhecendo a importância do seu papel como Rainha, na mudança que desencadeou na própria Inglaterra" (2009, p. 4). 
So strange, a book of empty pages. I have never seen in all my life a thing so very odd or very wonderful as this parchment diary. For different from a book that I might read whose author offers up to me like some rich meal, his thoughts and words and deeds, this empty volume defies and mocks me, begs of me to make its pages full. But full of what? (MAXWELL, 2012, p. 26).

É assim que ela inicia seu diário pessoal, datado em 4 de janeiro de 1522 , contando como aquele livro de páginas em branco viera parar em suas mãos, oferecido por Thomas Wyatt, um dos poetas mais famosos da corte inglesa da primeira metade do século XVI.

The Secret Diary of Anne Boleyn se configura numa das maiores obras da carreira de Robin Maxwell como romancista. Nas palavras de Susan Bordo (2013, p. 219):

Most novels about Anne were written in the 1980s and '9os had been quite sympathetic toward her. Maxwell's own book (1997) is constructed around the delightful fiction that Elizabeth discovers Anne's diary and learns how much her mother loved her and how 'cruel ad outrageously unjust' her father had been; the knowledge redeems Anne in her daughter's eyes and sets Elizabeth up for a lifetime of caution about giving the men in her life too much power:

Ou seja, o enredo do referido romance narra a trajetória de uma mulher no centro das atenções, que pouco sabia da vida de sua mãe. De repente, cai em suas mãos um diário dela, no qual a autora conta uma versão diferente sobre seu caso com o rei Henrique VIII, o nascimento da filha, e a própria morte.

Sendo assim, é interessante notar o pensamento feminino atual presente na trama, e que foi muito bem destacado por Bordo: Elizabeth, que no início do romance sofre por estar enamorada de Robert Dudley, em detrimento de seu dever como rainha, aprende com a história da ascensão e queda da própria mãe qual era o destino de mulheres que, por quererem ser algo além do que a sociedade permitia, perderam a própria vida ao sacrificarem tudo por um relacionamento. Em sua posição de soberana, ela gozava de maior privilégio e liberdade do que as demais, e então decide que, para reinar de forma absoluta, não deveria se submeter à vontade masculina. Essa força e independência, contudo, só é despertada nela após o conhecimento do diário secreto de sua mãe, que, por sua vez, ela carregará consigo por muitos anos.

Apesar de a rainha Ana Bolena não ter deixado de fato um livro contendo detalhes de sua vida escritos a próprio punho, o enredo contado no romance coincide com a história factual, exceto por algumas poucas passagens, como o fato de a rainha Ana ter seis dedos, ou ser envolvida com práticas de feitiçaria. De acordo com a maioria dos biógrafos de Ana, entre eles Eric Ives, seria improvável que uma dama 
portadora de deformações físicas chamasse a atenção de um homem tão asseado como Henrique, ainda mais porque no século XVI ainda persistia a crença de que a mãe passava todos os defeitos corporais para o filho, e uma criança debilitada passava longe das pretensões do rei. Não só isso: era atribuído às mulheres inclusive a formação do sexo do bebê na gestação, e caso a criança nascesse morta ou com qualquer tipo de problemas, a culpa seria sempre delas, mas nunca dos pais (DUNN, 2004, p. 83).

Em The Secret Diary of Anne Boleyn, essa perspectiva é apresentada quando Ana aborta um filho homem em princípios de 1536: "Diary,That which I most feared has come to pass. I have miscarried of my savior, for the small bloodied flesh expelled from my womb was clearly male..." (MAXWELL, 2012, p. 239). Uma vez que Henrique se casara com Ana Bolena na esperança de que ela gerasse um filho saudável, e esta, não conseguindo cumprir esse desejo, então as pessoas acusaram o aborto da rainha como resultado de possíveis práticas de bruxaria e, portanto, se fazia necessário que o rei arrumasse uma nova esposa o mais rápido possível.

Com efeito, a crença na existência de bruxas era admitida inclusive entre os ciclos mais eruditos, conforme observamos nas palavras de Jane Dunn (2013, p. 219):

Era naárea do sexo que mais se temiam e condenavam as atividades das bruxas. Uma bruxa era representada como a personificação das qualidades invertidas da condição feminina: enquanto as mulheres normais eram mais fracas que os homens e submissas, as feiticeiras eram duronas, com acesso ao poder proibido; enquanto as mulheres eram passivas sexuais, as bruxas eram vorazes em seus apetites e depravadas. Elas tinham conhecimento exclusivo de receitas para afrodisíacos e podiam fazer homens se apaixonarem perdidamente pelas mais improváveis mulheres até pelas cercadas de trevas como elas próprias:

Sendo assim, uma mulher com as características de Ana Bolena se constituía num prato cheio para aqueles que queriam acusá-la de bruxa e de manter relações com o diabo. Nesse caso, afirmar algumas deformidades físicas nela só endossaria ainda mais o argumento de que ela valeu-se de sortilégios para conquistar o rei (DUNN, 2004, p. 82).

No romance, quando retornara de seu exílio após o caso com Percy, Ana Bolena passara a integrar o séquito de damas da rainha Catarina, e possivelmente foi quando o rei interessara-se por ela. Não se sabe ao certo quando o envolvimento dos dois teve início, mas Robin Maxwell, na obra, data esse acontecimento em meados de 1526:

Diary, His Majesty pursues me still and I resist. He is a man in love, he says, giddy with it. It seems so. His dark mood is gone, reborn to manly vigor. In his Kingly role he moves aggressively again, his brilliant statesmanship restored. He speaks to me of 
family, his children and their marrying, His bastard son by Bessie Blount he sometimes thinks of wedding to his lawful daughter Mary. Anything, he says, is better than a woman ruling England. Women are not strong enough to keep the peace...(MAXWELL, 2012, p. 59).

A fala da personagem, ressalta perfeitamente a crença generalizada de que mulheres eram incapazes de governar. No caso da personagem Henrique, era preferível a ele ver seu filho bastardo no trono, a deixar que sua filha com Catarina de Aragão, Maria, o sucedesse. Dessa forma, ele pretendia pedir ao Papa uma dispensa para casar os dois filhos para que assim não fosse considerado pecado aos olhos de Deus.

Um ano depois, no decorrer da trama do romance, os planos de Henrique mudam: ele não mais queria encontrar uma forma de legitimar a sucessão de seu filho bastardo, mas sim contrair segundas bodas. Mais uma vez, a personagem Ana escreve em seu diário como foi o dia em que o rei lhe pediu em casamento:

Henry pressed and pressed, showering me with promises and kisses. 'I will marry you,' said he, 'marry you and put aside Katherine.' The words to pretty did ring false to me, for Katherine, of most royal Spanish blood, is loved by all and so devout she must have God's ear. But Henry was persuasive... (MAXWELL, 2012, p. 82).

Não obstante, uma vez que ela já gozava de poder e prestígio diante do rei, ela poderia usar dessa influência para conseguir coisas que antes não podia, entre elas, derrubar seus inimigos. Tal postura, entretanto, não era apreciável em mulheres da época, pois geralmente estavam ligadas a intrigas e conspirações, duas artes pouco louváveis em uma dama de família tradicional, por exemplo.

Uma rainha deverá ser casta, sensata, de gente honesta / ter boas maneiras e educar os seus filhos de forma normal / a sua sabedoria não deve resultar apenas em fatos e ações, mas também em falar do que deve saber e guardar segredo do que deve permanecer secreto... Uma rainha deve ter boas maneiras e, acima de tudo, deve ser temerosa e recatada (CESSOLIS apud LOADES, 2010, p. 12).

Naqueles anos, o grande modelo feminino na Inglaterra era a rainha Catarina de Aragão, especialmente pelo seu suposto caráter leal, piedoso, corajoso e compassivo (FRASER, 2010, p. 569). Ela personificava o modelo de esposa ideal, e, caso tivesse dado um filho saudável ao rei, é possível que esse não a teria repudiado, principalmente para não invalidar os direitos da criança à sucessão do trono. 
Nesse caso, é importante frisar que o papel de uma rainha consorte, antes de tudo, era o de fornecer uma prole numerosa de sucessores à coroa. Assuntos ligados à política, por sua vez, não eram tarefa delas, exceto em casos nos quais o rei dava uma brecha para isso, como o próprio Henrique fazia com a Catarina, e depois dessa, com Ana (LOADES, 2010, p. 14). A erudição era uma arte preferível aos homens. As mulheres, com efeito, supostamente deveriam cuidar da supervisão do lar e demais afazeres domésticos. Então, Ana Bolena, com sua carga de conhecimento humanista, personificava no imaginário popular, de então, o papel (de) alguém pronto para destruir o lar patriarcal da família tradicional inglesa. Inclusive, muitas das atitudes de Henrique, após o caso do divórcio ter se tornado de conhecimento público, foram atribuídas à influência da amante, especialmente a queda do chanceler, cardeal Wolsey. (DUNN, 2004, p. 8o).

A narrativa romanesca das últimas décadas do século XX e início do XXI, incluída em The Secret Diary of Anne Boleyn, conclui que Ana não gostava do cardeal, por acreditar que ele fora o pivô da separação entre ela e Henry Percy, no ano de 1522. Até mesmo George Cavendish, em seu Life of Wolsey, afirma que o ressentimento dela para com o chanceler se acirrou após esse episódio (FRASER, 2010, p. 171). Vejamos, então, como Maxwell apresenta a queda do cardeal, em 1529, na voz da personagem Ana Bolena:

My part in this was making Henry see that Wolsey was no friend, in deed was one who, brought down upon the King's head no end of trouble and disgrace. Whilst we walked in Greenwich garden with winds blowing leaves in swirls about our shoes, I lectured henry like some sharp tongued tutor.

"That great loan the Cardinal arranged to pay for your war against the French," said I, "has indebted every English subject in the realm worth five pounds, to you. But worse, your Cardinal's diplomatic blundering has left us now without the French as allies. All hisarse kissing of Francis wasted. England's place amongst the European powers lost".

Henry nodded gravely knowing what I said was true and this made me brave to then continue my incentive. "You have raised this Priest so high that his wealth fully one third of your own treasury, yet Wolsey has no country to run on his income. Do you know they call your English Cardinal the King of Europe?"

Henry winced as tho I'd struck him, for there ingrained within his seething anger for old Wolsey were both loyalty and love, and thus a pain within their parting. But there was no help for the man. His fate was sealed (MAXWELL, 2012, p. 136). 
Essa passagem demonstra na ficção de Maxwell não apenas a suposta intervenção de Ana na queda de um dos homens mais poderosos da Inglaterra, como também uma característica bastante peculiar de seu caráter: o domínio da retórica.

Conhecida como a arte dos advogados, a retórica era essencial para manter uma conversa inteligente, mas entre homens. Contudo, Ana era instruída nessa arte, e esta era uma de suas características que mais incomodavam a Henrique VIII. Vitoriosa, ela não só teria derrubado seus inimigos, como galgou o mais alto posto na escala social que uma mulher de ascendência comum poderia sonhar: a realeza. Essa passagem, no romance, é descrita da seguinte forma:

30 May 1533. Diary, Is it true? Dare I write the words? I am crowned Queen of England. Queen Anne. Anne the Queen. Anna Regina. The words placed together do seem right and fair. My heart now beats a normal rhythm, but in those hours of pageantry and celebration I feared several times that it might burst from equal parts of joy and terror (MAXWELL, 2012, p. 181).

Uma vez coroada rainha, não havia outra posição social à qual a personagem conseguiria subir. Dessa forma, ela só podia descer, e a queda, contudo, seria mais rápida do que a ascensão. Comparando esse aspecto do romance com a história, é interessante notar que Ana é representada por Robin Maxwell como uma espécie de jogadora, que apanhou o destino nas próprias mãos e seguiu em frente. Apenas no desfecho da narrativa é que ela perde o controle da situação, ficando à mercê de seus inimigos e da cólera do rei.

Avançando no enredo do romance, com o passar dos meses, o amor que Henrique VIII devotara àquela dama, verteu-se primeiro em indiferença, e depois em ódio e rancor, à medida que ela não dava um filho homem à coroa. Convencido de que seu segundo casamento era inválido diante dos olhos de Deus, o rei ordenou aos seus ministros que arrumassem provas que acusassem a própria esposa de traição. Não obstante, a personagem Ana Bolena quis de seu marido uma coisa que mulher nenhuma, na Europa do século XVI, tinha direito de exigir: a fidelidade conjugal. No exemplo de família monogâmica, apenas a eles era dado o direito de ter uma amante, pois às esposas pesava a seguridade dos bens familiares através de uma geração de filhos legítimos. Como Ana, em três anos de casamento, não cumpriu com esse dever, ela teoricamente deveria passar o lugar para outra pessoa. Mas essa é uma versão muito simples de ver os fatos. O rei queria se livra dela para contrair novas bodas, e o quanto antes.

As acusações de adultério com três homens da câmara do rei fora extraída a base de tortura física, do tocador de alaúde Mark Smeaton. Nesse caso, é compreensível que um homem em tais circunstâncias confesse qualquer coisa para aliviar seu sofrimento. Quanto ao irmão da rainha, George, a prova de incesto fora oferecida pela mulher dele, Jane Rochford, que não gostava da cunhada e temia cair em desgraça 
junto com a família Bolena. Em The Secret Diary of Anne Boleyn, é possível perceber o desespero da personagem, quando ela descreve sua situação:

I am a prisoner, Diary, a prisoner in the Tower of London. Woe to me for I am surely finished, accused of adultery, nay treason. For in England adultery practiced by a Queen is treason and treason is death. This is no just accusation to be argued in a court for its fair outcome. No a distant nunnery will never do, for Henry needs me dead (MAXWELL, 2012, p. 245).

Em sua fala, ela já deixa clara a situação em que se encontra: se para uma mulher, cometer adultério era um crime contra a moral e passível dos piores castigos, para uma rainha isso era sinônimo de apenas uma coisa, ou seja, a morte.

Acusando sua mulher de infidelidade, Henrique conseguiu o que queria. Livrou-se de um estorvo e se casou com Jane Seymour, que após lhe ter dado um filho varão, morreu poucos dias depois em consequência do parto.

Após ler todo o diário de sua mãe, a personagem Elizabeth, que antes tinha um grande fascínio pelo pai, toma uma grande resolução em sua vida: permanecer longe do poder dos homens. $\mathrm{O}$ romance termina com a seguinte passagem:

Elizabeth turned and swept from the chapel with the strength of destiny at her back, pulling the heavy doors closed with a resounding crash.

Yes, she thought as she strode out into the now sunlit afternoon, I am my mother's daughter. And I shall make her proud (MAXWELL, 2012, p. 281).

Com isso, Robin Maxwell apresenta para seus leitores uma nova interpretação acerca da história de Ana Bolena. A narrativa, entretanto, ainda continua em outro romance, intitulado The Queen's Bastard, pautado mais na figura da própria rainha Elizabeth e seus desafios como monarca.

A figura de Ana Bolena construída pela autora não condiz com o ideal de mulher passiva do século XVI, mas sim com o da força e determinação. Essa perspectiva é apresentada pela própria personagem, quando esta diz:

... In this world a woman is born with one master who is her Father. He rules her life until he hands her to a husband, who rules it till death. Many preachers preach that women have no souls. But some perverse twisting in myself has always kept me from obedience to men...(MAXWELL, 2012, p. 269).

Com isso, Maxwell oferece para seus leitores um enredo contextualizado em uma época na qual o pensamento conservador ditava o comportamento das classes 
sociais, porém com uma mensagem feminista própria dos tempos modernos. No desfecho de The Secret Diary of Anne Boleyn, a personagem Ana Bolena passa para sua filha, por meio de uma carta apócrifa, um apelo ao individualismo da mesma, na intenção de que essa não se submeta à vontade masculina. Conforme fora evidenciado anteriormente, segundo a concepção cristã do século XVI, a mulher deveria viver para o marido e a família, prezando por um comportamento que refletisse o recato e a virtude. Aquelas que fugissem a esse padrão eram logo vistas com desconfiança pela sociedade e ao mínimo deslize, seriam taxadas por uma série de apelidos, entre os quais o de bruxa. Apenas com o passar dos anos, esse quadro foi se alterando. Depois de muitas lutas, as mulheres modernas conseguiram maior participação na vida social e passaram a se unificar em prol de um interesse em comum: igualdade entre os sexos. Algo que era praticamente inexistente na Inglaterra do século XVI, mesmo tendo como soberana uma rainha reconhecida como umas das maiores monarcas da história daquele país, ou seja, Elizabeth I.

Na suposta carta que a personagem Ana Bolena deixa para a filha, lê-se o seguinte trecho:

So, daughter, to I have suffered and shall soon die for this selfish need to rule my fate, I beg of you to the same. Let no man be your master. Love, lust, marry if you will, but hold apart from all men a piece of your spirit. This thus that I shall grasp the headsman's block with no regrets and never be afraid of death...(MAXWELL, 2012, p. 270).

O apelo feito por Ana Bolena denota um caráter de independência da mulher. Para Elizabeth ser dona de si, ela então deveria guardar dos homens a parte principal de seu próprio caráter, se possível, seria de preferência que sequer contraísse matrimônio. Estaria Robin Maxwell, com seu romance, diagnosticando assim uma crise da família tradicional já na Inglaterra renascentista? Numa primeira leitura da obra, é provável que não, mas através de análises secundárias, podemos identificar no discurso da autora alguns elementos que já antecipavam o perfil da mulher moderna, principalmente através da personagem Elizabeth.

\section{Considerações finais}

Em várias passagens de The Secret Diary of Anne Boleyn, a personagem da rainha Ana questiona seu papel no mundo como mulher, algo que fica bastante evidente no desfecho da obra, quando ela diz que seu erro fora querer ser mais do que lhe permitiam, mas que, não obstante, morria com a consciência tranquila. Era a leitora de livros proibidos; inconformada com a subordinação das mulheres aos homens, a quem os chama de traidores; mulher e mãe. Ana Bolena, depois do período das Guerras Mundiais, retornara para o mundo da ficção com mais força 
e independência que antes. Nesse sentido, a própria luta das mulheres pela sua emancipação constituíra-se num fator decisivo para que romancistas, a exemplo de Robin Maxwell com sua obra de 1997, repensassem o papel da rainha Ana na sociedade inglesa quinhentista. De acordo com BORDO (2013, p. 171), "passive, dependent heroines were no longer appreciated by meddle-class female readers, who during the war had not only their own independence tested, but who also had been treated, at the movies and women's magazine, to feisty, spirited female character". Desse modo, a história de Ana Bolena caiu no gosto popular, especialmente em romances como os de Maxwell, cuja figura da mulher é relacionada à força e determinação, enquanto os homens são vistos como fracos e cheios de vícios.

Até o século XIX, Ana Bolena havia sido representada como uma concubina, amante do rei e causadora dos males da Inglaterra. Contudo, a partir do século XX, nota-se um reparo em sua imagem, e a literatura assumiu um grande papel nessa questão. Romancistas como Jean Plaidy em Muder Most Royal (1949), Norah Lofts em The Cuncubine (1963) e mesmo Robin Maxwell em The Secret Diary of Anne Boleyn (1997) optaram por mostrar ao público uma Ana diferente daquela registrada pela crônica do século XVI, denotando na mesma características que a tornavam simpática aos olhos modernos, especialmente para as mulheres, que se tornariam uma das principais defensoras desta personagem. A maioria dos pesquisadores que se debruçaram sobre a história da segunda esposa de Henrique VIII é composta pelo público feminino, como é o caso destas romancistas citadas anteriormente, e das historiadoras Antonia Fraser e Alison Weir (2009), autoras de biografias de sucesso sobre Ana Bolena.

Não obstante, o fato de ter sido mãe de uma das soberanas mais famosas da história inglesa, como Elizabeth I, pode ter sido outro fator que despertou nas pessoas o interesse em resgatar o passado de Ana, e de como a história dela foi fundamental para o crescimento de sua filha, tanto como mulher, como soberana. É isso que Maxwell faz em seu romance, apesar de os registros apontarem que "Elizabeth I nunca pensou em reabilitar a reputação de sua mãe, muito menos em fazer uma identificação mais adequada do túmulo da mulher que a dera à luz" (FRASER, 2010, p. 562). Uma vez que Elizabeth havia sido declarada bastarda, e nunca se livrou desse estigma, o discurso mais lógico que ela poderia usar era o de enfatizar seu direito ao trono pelo lado paterno, e, com isso, "distanciar-se das sombrias circunstâncias da morte de sua mãe" (ibidem). Nesse caso, caberia ao leitor se perguntar: por que Robin Maxwell resolveu criar uma trama na qual a filha descobria o diário de sua mãe e passava a admirá-la?

Em tese, poderíamos supor que simplesmente para vender uma imagem de Ana Bolena como heroína trágica e modelo de mulher a ser seguido. Contudo, o que Maxwell fez foi apresentar dois perfis de mulheres que, não obstante, se assemelhavam em muitos aspectos. Baseada em pesquisa bibliográfica e em fontes, ela conseguiu criar uma trama inteligente na qual uma mulher do passado dialogava com sua filha através das páginas de um diário. Depois da leitura desse livro, o caráter de Elizabeth sofre uma transformação. Mas seria essa Elizabeth a representação da rainha que 
governou a Inglaterra de 1558 a 1603, ou seria ela o próprio leitor, que encontra numa obra de ficção literária elementos com os quais possa se identificar? Com efeito, é possível dizer que Elizabeth é o próprio leitor, que antes julgara a figura de uma mulher pelas falácias do passado e, depois de terminada a leitura do romance, passa a enxergar a mesma com outros olhos. Sendo assim, o cruzamento da narrativa literária com a narrativa histórica pode oferecer um novo viés para se pensar não apenas o tempo vivido, como o nosso presente e até mesmo nossas perspectivas para o futuro.

\section{Referências Bibliográficas:}

ALMEIDA, Ana Paula Lopes Alves Pinto de. Ana dos mil dias: Ana Bolena, entre a luz e a sombra da Reforma Henriquina. Porto, 2009. Dissertação (Mestrado em Letras). Faculdade de Letras da Universidade do Porto.

BORDO, Susan. The creation of Anne Boleyn: a new look at England's most notorious queen. - New York: Houghton Mifflin Harcourt, 2013.

BRICHTA, Laila. As Histórias nas páginas deuma romance:análiseda representação de ditadura na obra El Otoño Del Patriarca. Campinas, 2002. Dissertação (Mestrado em História). - Instituto de Filosofia e Ciências Humanas, Universidade Estadual de Campinas.

CHARTIER, Roger. A verdade entre ficção e história. In: SARPA, Élio Cantalício et.al. (org.). Narrativas da modernidade: história, memória e literatura. - Uberlândia: EDUFU, 2011, p. 213-228.

_. O mundo como representação. In: Estudos Avançados. Vol. 5 n.ํ 11, São Paulo, Jan./ Abr. 1991.

DUNN, Jane. Elizabeth e Mary: primas, rivais, rainhas. Tradução de Alda Porto. - Rio de Janeiro: Rocco, 2004.

FRASER, Antonia. As Seis Mulheres de Henrique VIII. Tradução de Luiz Carlos Do Nascimento E Silva. 2ª edição. Rio de Janeiro: BestBolso, 2010.

IVES, Eric W. The life and death of Anne Boleyn: 'the most happy'. - United Kingdom: Blackwell Publishing, 2010.

LE GOFF, Jacques; NORA, Pierre et. al. História: novos problemas. - Rio de Janeiro: Francisco Alves, 1995. 
LIMA, Luiz Costa. História Ficção Literatura. - São Paulo: Cia das Letras, 2006.

LINDSEY, Karen. Divorced, Beheaded, Survived: A Feminist Reinterpretation of the Wives of Henry VIII. - Cambridge, M A: Da Capo Press, 1995.

LOADES, David. As Rainhas Tudor: o poder no feminino em Inglaterra (séculos XVXVII). Tradução de Paulo Mendes. - Portugal: Caleidoscópio, 2010.

MAXWELL, Robin. The secret diary of Anne Boleyn. - New York: Touchstone Book, 2012.

PESAVENTO, Sandra Jatahy. O mundo como texto: leituras da história e da literatura. In: História e educação, ASPHE/FaE/UFPel, Pelotas, n. 14, p. 31-45, set. 2003.

_. Relação entre História e Literatura e representação das identidades urbanas no Brasil (século XIX e XX). In: Revista Anos 9o, Porto Alegre, n. 4, dezembro de 1995.

_. História e Literatura: uma velha-nova história. In: Nuevo Mundo Mundos Nuevos, Debates, 2006. Disponível em: http://nuevomundo.ruvues.org/document156o.html. Acesso em 1 de setembro de 2016.

RAMOS, Danielle Cristina Mendes Pereira. Memória e Literatura: contribuições para um estudo dialógico. In: Linguagem em (Re)vista, ano 6, n 11/12. Niterói, 2011.

WEIR, Alison. The lady in the tower: the fall of Anne Boleyn. - New York: Ballantine Books, 2010.

WHITE, Hayden. Meta-história: a imaginação histórica do século XIX. Tradução de José Laurênio de Melo. 2ª ed. São Paulo: Editora da Universidade de São Paulo, 2008.

_. Teoria Literária e escrita da História. In: Revista Estudos Históricos, Rio de Janeiro, CPDOC/Fundação Getúlio Vargas 7 (13): 21-48, 1994.

Recebido: 01.10.2017

Aceito: 07.09.2018 